BMJ Open Sport \& Exercise Medicine

\section{Potential for reduced premature mortality by current and increased bicycle commuting: a health impact assessment using registry data on home and work addresses in Stockholm, Sweden}

To cite: Sommar JN, Schantz P, Strömgren M, et al. Potential for reduced premature mortality by current and increased bicycle commuting: a health impact assessment using registry data on home and work addresses in Stockholm, Sweden. BMJ Open Sport \& Exercise Medicine 2021;7:e000980. doi:10.1136/ bmjsem-2020-000980

Accepted 7 January 2021
Check for updates

(C) Author(s) (or their employer(s)) 2022. Re-use permitted under CC BY. Published by BMJ.

${ }^{1}$ Department of Public Health and Clinical Medicine, Section of Sustainable Health, Umea University, Umea, Sweden

${ }^{2}$ The Research Unit for Movement, Health and Environment, The Swedish School of Sport and Health Sciences, GIH, Stockholm, Sweden

${ }^{3}$ Department of Geography, Umea University, Umea, Sweden

Correspondence to Dr Johan Nilsson Sommar; johan.sommar@umu.se

\section{ABSTRACT}

Objectives The study aims to make use of individual data to estimate the impact on premature mortality due to both existing commuter bicycling and the potential impact due to increased physical activity through shifting transport mode from car commuting to bicycling.

Methods Using registry data on home and work addresses for the population of Stockholm County the shortest bicycling route on a network of bicycle paths and roads was retrieved. Travel survey data were used to establish current modes of commuting. The relation between duration of bicycling and distance bicycled within the general population in $\mathbf{2 0 1 5}$ was established as a basis for identifying individuals that currently drive a car to work but were estimated to have the physical capacity to bicycle to work within $30 \mathrm{~min}$. Within this mode-shift scenario from car-to-bike the duration of bicycling per week was estimated, both among current and potential bicycle commuters. The health impact assessment (HIA) on mortality due to bicycle commuting physical activity was estimated using the same relative risk as within the WHO Health Economic Assessment Tool.

Results The current number of bicycle commuters were 53000 , and the scenario estimated an additional 111 000 . Their mean bicycle distances were 4.5 and $3.4 \mathrm{~km}$, respectively. On average these respective amounts of physical activity reduced the yearly mortality by $16 \%$ and $12 \%$, resulting in 11.3 and 16.2 fewer preterm deaths per year.

Conclusion The HIA of transferring commuting by car to bicycle estimated large health benefits due to increased physical activity.

\section{INTRODUCTION}

Local measures are taken to increase bicycling in many cities to decrease urban air pollution concentrations and decrease traffic congestion. This also has the additional benefit of increasing the amount of physical activity. Such interventions are of great public health

\section{What are the new findings?}

The study uses travel survey-data and registry-data on home and work addresses to identify 53000 actual commuting trips currently made by bicycle, with 20 min estimated average bicycle duration.

- Using empirical time-distance relationships among current commuters in the same population an additional 111000 current car commutes with the estimated physical capacity to bicycle to work within 30 min were identified, with an estimated average bicycle duration of $15 \mathrm{~min}$.

- The study found that among current bicycle commuters the risk of 1-year mortality is on average reduced by $16 \%$, and that the mortality risk would be reduced by $12 \%$ among the potential bicycle commuters if they opt to change their mode of commuting from car to bike.

importance since both lack of physical activity and exposure to air pollution are among the leading risk factors for non-communicable disease. ${ }^{1}$ Non-communicable chronic diseases accounts for nearly half of the overall global burden of disease, and 6 out of 10 deaths are attributable to non-communicable disease. ${ }^{2}$

The health benefits of active commuting (transport to work by walking and bicycling) has been summarised in a systematic review of prospective observational studies and intervention studies concluding that active transport has significant effects on morbidity and mortality. ${ }^{3}$ The World Health Organization (WHO) has developed a Health Economic Assessment Tool (HEAT) based on a meta-analysis of mortality in relation to active commuting to estimate the expected reduction in mortality and the economic implication for an increased amount of bicycling and walking in a population. The 
estimated risk reduction by performing the WHO recommended minimum amount of physical activity was $10 \%$ (95\% CI $6 \%$ to $13 \%$ ) for bicycling. ${ }^{4}$ This relative risk has been used in several health impact assessments (HIAs) of the benefit of current bicycling and for different transport scenarios.

HIAs of bicycling have been conducted both for scenarios of increased bicycling ${ }^{5-15}$ and to assess health impacts of bicycle sharing systems. ${ }^{16} 17$ The HIAs include health benefits due to increased physical activity, increased air pollution exposure among those that increase their amount of bicycling, reduced air pollution exposure during previous amounts of bicycling and reduced air pollution exposure within the general population. Most of the studies estimated that the majority of the health impact was due to increased physical activity. To our knowledge no previous study has conducted an HIA of increased physical activity based on actual individual commuting trips between home and work. Such individual estimates of physical activity using registry data also enables considering individual differences in bicycling speed.

This study therefore aims to, based on individual registry information on home and work addresses, shortest travel route and empirical bicycling speeds within the study population, estimate the impact on premature mortality due to both existing commuter bicycling and the potential impact due to increased physical activity through shifting transport mode from car commuting to bicycling in case the calculated cycle trip can be undertaken within 30 min or less.

\section{METHODS}

\section{Defining current and alternative modes of commuting}

Current modes of travel

Based on travel survey data the proportion currently travelling to work with each mode of transport; walking, bicycling, public transport and car, was estimated. To estimate these proportions, individual survey responses were aggregated to small statistical areas within Stockholm County, Sweden. The size of areas was determined by the population density but also taking into consideration natural geographical divisions between areas.

Together with data on traffic flows on roads and estimated proportions of individuals using different modes of travel, the LuTrans transport model for Stockholm County was constructed. Within the LuTrans transport model the travel survey data were used to allocate individual trips to different modes of travel. To obtain the route taken as driver of car, traffic counts was used to allocate car trips to different roads. The model outputs the traffic flow on each road link in the model, where a link is defined as the connection between two major intersections in the road network. LuTrans has been regularly calibrated based on repeated traffic counts.

Using this model all inhabitants (at least 16years of age) with a home and work addresses within Stockholm County were allocated to a current mode of transport. The construction of the scenario has been described in more detail by
Strömgren et al. ${ }^{18}$ This allocation also considered individual data on car ownership. Individual information on age, gender, car ownership and home and work address were obtained from the ASTRID database. ${ }^{19}$

\section{Alternative scenario}

Expected bicycling speeds were based on a previously published study using empirical data on distance and bicycling time within a sample of 455 existing male and female bicycle commuters within the population of Greater Stockholm. ${ }^{20}$ The participants in that study were recruited through advertisements in newspapers. The details of the recruitment and the sample characteristics has been described by Schantz. ${ }^{21}$ The participants drew their own normal bicycle commuting route to work on a map, and its distance was measured using a criterion method. ${ }^{22}$ The bicycling time was measured and self-reported by the participants and was instructed to be without any errands on the way. The procedure has been described in detail by Schantz. ${ }^{21}$ Such a sample of current bicycle commuters may however not represent the time-distance relationship within the general population. Therefore, expected bicycling speeds were scaled down according to the relative difference in maximum oxygen uptake between current bicycle commuters and a sample from the general population. This scaling was performed separately within gender and age groups. Since the general population sample and the sample of current commuters were observed years apart, the relative difference was scaled according to gender specific time trends in body mass index within the population. This scaling of expected bicycling speeds to represent the general population has been described in detail by Schantz et $a l,{ }^{202324}$ where resulting bicycle speeds estimated by gender stratified linear regressions were given by speed $(\mathrm{km} /$ hour $)=0.719 \times(34.8+0.31 \times$ age $)$ among men and speed $(\mathrm{km} /$ hour $)=0.763 \times(25.9+0.21 \times$ age $)$ among women, and where age was measured in years and 0.719 and 0.763 represents the bicycle commuter to the general population effect among men and women, respectively.

This model predicting bicycling speed was used to identify the individuals that have the potential to bicycle to their workplace within $30 \mathrm{~min}$. Registry data on age and gender was retrieved from the ASTRID database. The database also informed about individual home and work address coordinates by which the shortest path along a network of possible roads and bicycle paths was determined. If the individual was estimated to have the potential to bicycle to work within $30 \mathrm{~min}$ based on age and gender, and the individual was previously allocated as travelling to work by car, the individual will in the scenario switch to be travelling by bicycle.

\section{Estimating the amount of physical activity}

Using the individual's shortest path bicycling distance between home and work and the individual's expected bicycle speed based on age and gender, the bicycling time was estimated. A constant average bicycling speed was assumed. The bicycling intensity was assumed to be 6.8 
Table 1 Frequencies and proportions of the individuals using different types of transport

\begin{tabular}{|c|c|c|c|c|c|c|}
\hline \multirow[b]{2}{*}{ Mode of transport } & \multicolumn{2}{|l|}{ Current situation } & \multicolumn{2}{|l|}{ Mode-shift scenario } & \multicolumn{2}{|c|}{ Difference and corresponding proportion } \\
\hline & Number of individuals & Proportion (\%) & Number of individuals & Proportion (\%) & Number of individuals & Proportion (\%) \\
\hline Bicycling & 53206 & 6 & 164693 & 18 & 111487 & 210 \\
\hline Walking & 130441 & 14 & 130441 & 14 & 0 & 0 \\
\hline Public transport & 352412 & 38 & 352412 & 38 & 0 & 0 \\
\hline Car (driver) & 352614 & 38 & 241127 & 26 & -111487 & -32 \\
\hline Car (passenger) & 35297 & 4 & 35297 & 4 & 0 & $0 \%$ \\
\hline
\end{tabular}

MET based on measurements for bicycle commuting. ${ }^{25}$ Thereafter the yearly amount (MET-hours/week) of physical activity was estimated assuming four round trips a week 45 weeks a year.

\section{Health impact calculations}

Using the relative risk (RR)-function for all-cause mortality in relation to bicycling used within HEAT, ${ }^{4}$ the reduced number of yearly premature deaths with increased physical activity was calculated. The risk reduction implemented was $10 \%$ (95\% CI 6\% to 13\%) for the standardised amount of physical activity corresponding to 11.25 MET-hours/week. This RR is the result of a metaanalysis of seven studies. Six of these studies were based on populations within Western Europe (four from Denmark and one study from UK and Germany, respectively). The bicycling assessed was predominantly commuting. All but one study reported a reduced risk of all-cause mortality with bicycling. The meta-analysis was based on 187000 individuals observed during in total 2.1 million personyears. The mean age during the follow-up was 56.6 years of age, ranging between 20 and 93 years.

As within HEAT, a straight-line association between physical activity and mortality was assumed with a maximum risk reduction at $447 \mathrm{~min}$ of bicycling per week. Age and gender specific mortality data for Stockholm County was used to estimate the impacts on mortality and life-table calculations was used to calculate expected remaining life years based on age and gender. ${ }^{26}$

The public was not involved in the design, or conduct, or reporting, or dissemination plans of the research.

\section{RESULTS}

\section{Effects on mode of commuting}

Of a total of 923970 current commuters with a home and work address within Stockholm County, approximately $53000(6 \%)$ were currently estimated to bicycle and 350 000 to be driver of a car $(38 \%)$ (table 1$)$. The mean age among individuals were 41.8 years and $49 \%$ were women. In the scenario that would change to approximately 165 000 bicyclists, an increase to $18 \%$ bicycle commuters. This corresponded to approximately 111000 additional bicyclists. The mean age among the additional cyclists was 42 years and $48 \%$ was women. Age-specific number of current and additional bicyclists showed that the proportion of bicyclists less than 35 years of age was higher among current bicycle commuters (table 2).

\section{Estimated amounts of physical activity from bicycle commuting}

The mean travel distance to work was $4.5 \mathrm{~km}$ among current cyclists compared with $3.4 \mathrm{~km}$ among the additional cyclists in the scenario. Estimated current and scenario travel time distributions are presented in figure 1 where the respective mean travel times were $20 \mathrm{~min}$ and $15 \mathrm{~min}$.

Assuming that the bicycle commuters on average make four round trips per week, 45 weeks a year, with an average bicycling intensity of $6.8 \mathrm{MET}$, the average amount of physical activity achieved among the additional bicyclists was 13.3 MET-hours/week. The distribution of the increased physical activity was presented in figure 2 ,

Table 2 Age-specific number of current and additional bicyclists, average distance and estimated speed and travel time between home and work, and impact on mortality risk and expected number of yearly prevented premature deaths

\begin{tabular}{|c|c|c|c|c|c|c|}
\hline Age (years) & Number (\% of bicyclists) & Distance (km) & $\begin{array}{l}\text { Bicycling speed } \\
\text { (km/hour) }\end{array}$ & Travel time $(\min )$ & Risk reduction (\%) & $\begin{array}{l}\text { Number of prevented } \\
\text { premature deaths }\end{array}$ \\
\hline \multicolumn{7}{|c|}{ Current bicycle commuters } \\
\hline$<35$ & $21662(41)$ & 4.7 & 16.2 & 17.8 & 14 & 0.4 \\
\hline $36-50$ & $17736(33)$ & 4.6 & 13.5 & 20.7 & 17 & 2.1 \\
\hline$>50$ & $13808(26)$ & 4.1 & 10.7 & 23.3 & 18 & 8.8 \\
\hline All & 53206 & 4.5 & 13.9 & 20.2 & 16 & 11.3 \\
\hline \multicolumn{7}{|c|}{ Additional bicyclists in the mode-shift scenario } \\
\hline$<35$ & $35945(32)$ & 4.1 & 16.5 & 15.0 & 12 & 0.6 \\
\hline $36-50$ & 45485 (41) & 3.4 & 13.6 & 14.8 & 12 & 3.8 \\
\hline$>50$ & $30057(27)$ & 2.5 & 10.8 & 13.8 & 11 & 11.8 \\
\hline All & 111487 & 3.4 & 13.8 & 14.6 & 12 & 16.2 \\
\hline
\end{tabular}




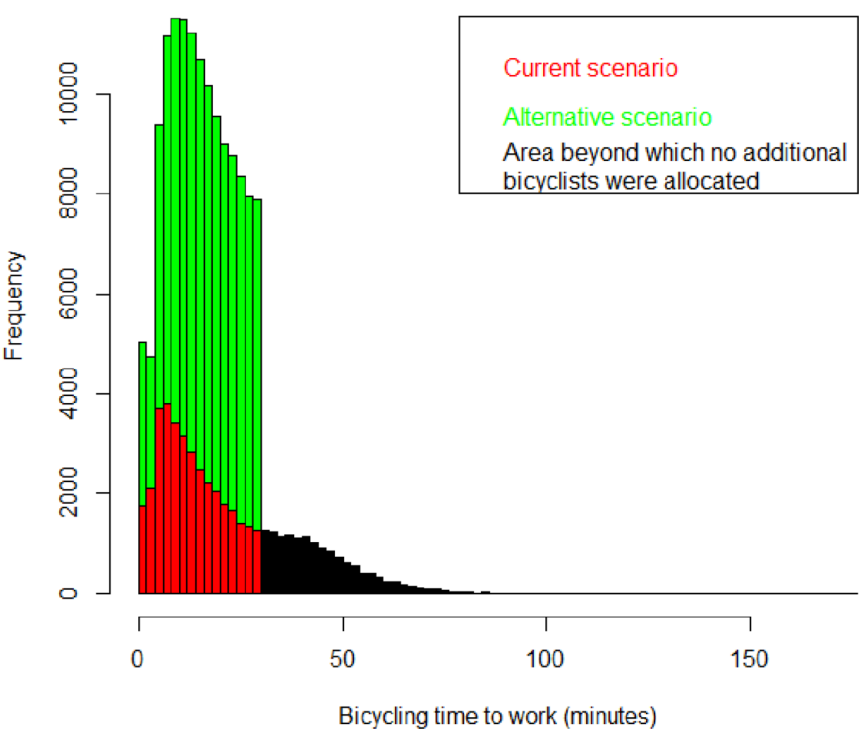

Figure 1 Distributions of expected bicycling times for current cyclists (red and black areas, where the black area indicates the part of the time distribution where no additional cyclists were allocated) and additional cyclists within the carto-bike scenario (green area).

where individual amounts of physical activity ranged up to 27.2 MET-hours/week.

\section{Estimated impact on mortality}

Based on the RR-function for yearly mortality used within HEAT, with a $10 \%$ risk reduction per 11.25 MET-hours/ week, the risk of yearly mortality among additional cyclists was reduced by up to $25 \%$ (figure $3 \mathrm{~A}$ ) and among current cyclists by up to $45 \%$. The average risk reduction

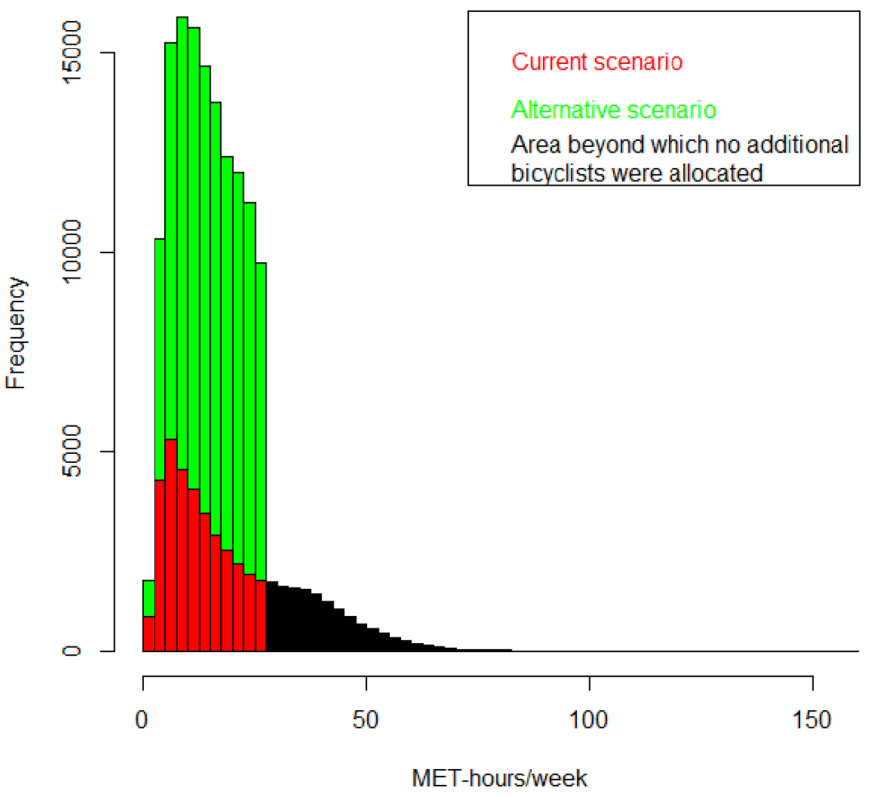

Figure 2 Distributions of expected amount of physical activity achieved among current cyclists (red and black areas, where the black area indicates the part of the distribution where no additional cyclists are present) and additional cyclists within the car-to-bike scenario (green area).
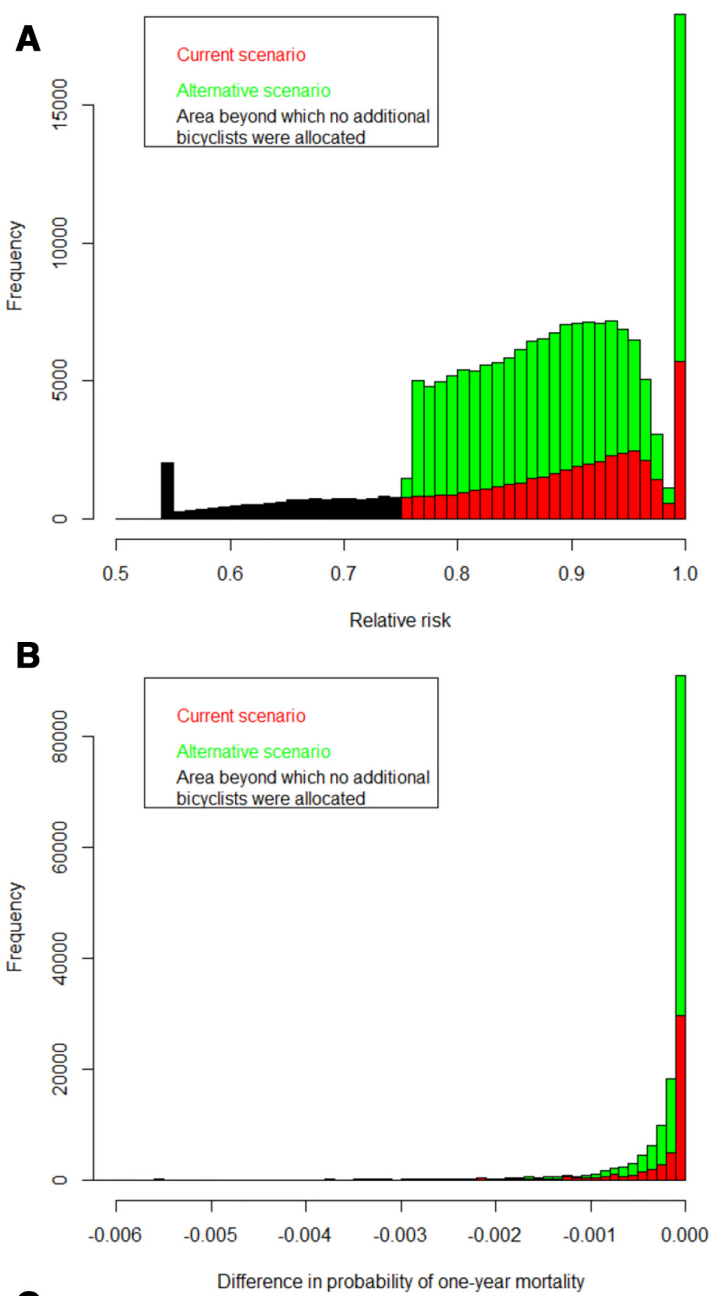

C

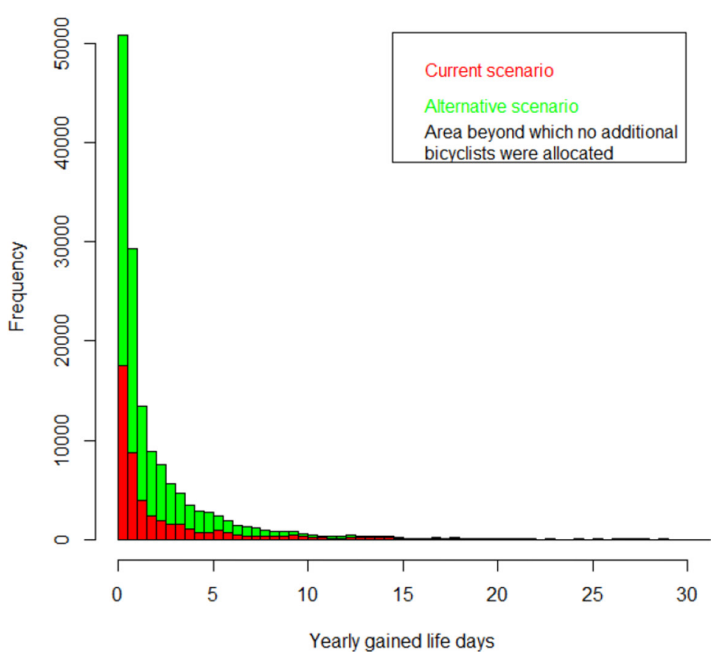

Figure 3 (A) Distributions of relative risks of yearly mortality among current cyclists (red and black areas, where the black area indicates the part of the distribution where no additional cyclists are present) and additional cyclists within the car-to-bike scenario (green area). (B) Distributions of the difference in risk of 1-year mortality comparing driving a car with cycling to work, among current cyclists (red areas) and additional cyclists within the car-to-bike scenario (green area). (C) Distributions of expected yearly gained life days among current cyclists (red areas) and additional cyclists within the car-to-bike scenario (green area). 
among additional cyclists was $12 \%$ and among current $16 \%$. Using registry data on baseline age and gender specific mortality for Stockholm County the resulting impact on mortality for this amount of current and additional bicycling was estimated to be 11.3 and 16.2 yearly prevented premature deaths, respectively (figure 3B). By applying life-table methods these respective number of premature deaths were estimated to correspond to 312 and 469 yearly gained life years (figure 3C). Age-specific risk reductions and expected number of yearly prevented premature deaths showed that $78 \%$ and $72 \%$ of the expected impact on mortality, for current and additional bicyclists, were among individuals older than 50 years of age (table 2).

\section{DISCUSSION}

This is the first study assessing the health impacts of physical activity in a scenario of increased bicycling based on registry data on home and work addresses. The on average $16 \%$ risk reduction for yearly mortality among current bicycle commuters corresponded to 11.3 avoided premature deaths. Additionally, in a scenario where individuals that currently commute by car would start to commute by bicycle if they were estimated to have the individual capacity to bicycle to their workplace within $30 \mathrm{~min}$, the yearly mortality was estimated to be reduced by 16.2 premature deaths each year.

The amount of physical activity obtained from bicycling was estimated based on the bicycling time and intensity, where the bicycling time was estimated based on assumptions about bicycling speed. Woodcock et al assumed that the bicycling speed ranged between 12 and $16 \mathrm{~km} /$ hour dependent on scenario bicycling infrastructure and waiting times. ${ }^{15}$ Rojas-Rueda et al calculated amounts of physical activity based on an average bicycle speed of $14 \mathrm{~km} /$ hour. ${ }^{11}$ Previous HIAs have also used similar physical activity intensities. As in the current study, Woodcock et $a l^{15}$ for instance used 6.8 MET as the average bicycling intensity, and the same bicycling intensity was assumed within each of their scenarios. A similar average intensity was used by Rojas-Rueda $e t a l,{ }^{11} 6$ MET.

Most commonly previous HIAs have also assumed a linear dose-response between the amount of bicycling physical activity and reduced risk of yearly premature mortality, with a maximum risk reduction of $50 \%$ as used by the WHO tool HEAT. ${ }^{6} 151727$ However, the empirical evidence suggest that this association is rather non-linear. ${ }^{148}$ Such dose-response functions have been applied in some studies, such as Woodcock et $a l^{15}$ but with the added uncertainty about the reference amount of physical activity.

In assessing the health impacts of increased bicycling, it is also necessary to make assumptions of how this affects other physical activity domains. It is possible that increased physical activity through active commuting replaces other types of physical activity, but it is also possible that increased active commuting leads to more physical activity in general. Longitudinal epidemiological studies have found that walking and bicycling add to the total amount of physical activity without reducing other types of physical activity. ${ }^{29} 30$

All previous HIA studies on increased bicycling, or assessments of health impacts of bike sharing systems, have reported great health benefits with reduced mortality due to increased physical activity. According to a review of HIA studies between $12 \%$ and $99 \%$ of the total impact on health was attributed to increased physical activity. ${ }^{31}$ Lower proportions were reported by Dhondt et $a l^{6}{ }^{6}$ Grabow et $a l^{32}$ and Holm et al. ${ }^{7}$ The scenario considered by Dhondt et at considered the impact from a $20 \%$ increase in fuel price. Expected to increase the number of bicycled kilometres by on average $2 \%$, but with greater increases in public transport, the largest impact was observed due to a reduced risk for injury in traffic accidents and reduced air pollution exposure within the population. Grabow et $a l^{32}$ estimated health impacts from transferring $50 \%$ of car trips $<8 \mathrm{~km}$ round trip to bicycle. Within the fairly densely populated US region population, and consideration of both fine particles and ozone, almost half of the impact was observed to be due to reduced air pollution exposure within the general population. Increasing the amount of bicycling in Copenhagen, Denmark, Holm et $a l^{7}$ found that the benefit of increased physical activity would be reduced by two-thirds due to an increase in number of accidents.

The estimated large health impact by reducing premature mortality within this and previous HIAs supports interventions and policies to increase active commuting. The amounts of physical activity through bicycle commuting observed in this study among current, and also estimated among potential additional bicyclists, also indicate that this form of physical activity may reach the $150 \mathrm{~min} /$ week physical activity level recommended by WHO. In a review of HIAs of bicycling Mueller $e t a l^{11}$ identified seven studies comparing estimated benefits of increased bicycling to corresponding intervention costs, six of the studies all estimated cost-beneficial effects whereas in one study the result was dependent on the type of intervention considered. The interventions included for instance bicycle infrastructures such as bicycle lanes, encourage use of pedometers and mass media-based community campaigns. As part of the Physical Activity Through Sustainable Transport Approaches project, a review and synthesis of published frameworks of active travel behaviour illustrated examples of pathways to achieve mode-shifts towards bicycling as assessed in the current study. ${ }^{33}$ In their study they for instance highlighted the effects of cycling highway infrastructure where regular bicyclists were affected by gaining more direct, pleasant and safer routes and potential bicyclists by an increased perceived safety that could increase their likelihood to pursue their intention to bicycle or pick up bicycling. 


\section{Strengths and limitations}

A strength compared with previous studies is that the study benefitted from the use of individual registry data for the entire study population including home and work address coordinates, which made it possible to perform an HIA of actual commuting trips. Using a network of bicycle paths and roads available for bicycling we were also able to extract the shortest bicycling path between home and work. The individual capacity to bicycle this distance between home and work was assessed by using age and gender specific bicycling speeds based on empirical time-distance relationship data within the study population. A limitation of this assessment is the use of an average intensity (MET-values) for bicycle commuting. This was necessary since studies on bicycle commuting intensities for individual bicycling speeds were lacking. That the values used are reasonable given the average speed applied are supported by recent measurements of bicycle commuting in Greater Stockholm, given that their bicycling velocities were higher. ${ }^{34}$ The usage of an average bicycling intensity affected individual estimates of the amounts of physical activity, however not the average amount or the total impact on mortality. Another limitation was the arbitrary choice of $30 \mathrm{~min}$ as the upper limit for the one-way bicycling time between home and work was arbitrary, but the choice aimed to create a reasonably realistic scenario in terms of bicycling time. The average commuter bicycling time in the scenario was found to be considerably lower among the added cyclists compared with current cyclists suggesting that obtained amounts of bicycling could be achievable.

\section{CONCLUSION}

This HIA using registry data on individual's home and work addresses, and retrieving shortest travel routes along a road and bicycle path network, estimated large health benefits due to increased physical activity by transferring commuting trips by car to bicycle.

Contributors JS performed health impact calculations and drafted the manuscript. MS was responsible for the random allocation of commuting modes within the ASTRID database. BF was the principal investigator and responsible for the project. $\mathrm{PS}$ and BF contributed to the drafting of the manuscript. All authors contributed to the interpretation of the results, read and approved the final manuscript.

Funding This work was funded by the Swedish Research Council for Health, Working Life and Welfare (grant number 2012-1296). The paper reflects only the authors views, and the funder had no role in the design or conduct of the study.

Competing interests None declared.

Patient consent for publication Not required.

Provenance and peer review Not commissioned; externally peer reviewed.

Data availability statement № data are available.

Open access This is an open access article distributed in accordance with the Creative Commons Attribution 4.0 Unported (CC BY 4.0) license, which permits others to copy, redistribute, remix, transform and build upon this work for any purpose, provided the original work is properly cited, a link to the licence is given, and indication of whether changes were made. See: https://creativecommons.org/ licenses/by/4.0/.

\section{ORCID iD}

Johan Nilsson Sommar http://orcid.org/0000-0002-8854-498X

\section{REFERENCES}

1 WHO. World Health organization. Global health risks: mortality and burden of disease attributable to selected major risks, 2009 Genewa, Switzerland, 2009. Available: http://www.who.int/ healthinfo/global_burden_disease/GlobalHealthRisks_report_full. pdf

2 Mathers C, Fat DM, Boerma JT. The global burden of disease: 2004 update: World Health Organization 2008.

3 Saunders LE, Green JM, Petticrew MP, et al. What are the health benefits of active travel? A systematic review of trials and cohort studies. PLoS One 2013;8:e69912.

4 Kelly P, Kahlmeier S, Götschi T, et al. Systematic review and metaanalysis of reduction in all-cause mortality from walking and cycling and shape of dose response relationship. Int J Behav Nutr Phys Act 2014;11:132.

5 de Hartog J, Boogaard H, Nijland H, et al. Do the health benefits of cycling outweigh the risks? Environ Health Perspect 2010;118:1109-16.

6 Dhondt S, Kochan B, Beckx C, et al. Integrated health impact assessment of travel behaviour: model exploration and application to a fuel price increase. Environ Int 2013;51:45-58.

7 Holm AL, Glümer C, Diderichsen F. Health impact assessment of increased cycling to place of work or education in Copenhagen. BMJ Open 2012;2:ARTN e001135. doi:10.1136/ bmjopen-2012-001135

8 Johansson C, Lövenheim B, Schantz P, et al. Impacts on air pollution and health by changing commuting from car to bicycle. Sci Total Environ 2017;584:55-63.

9 Maizlish N, Woodcock J, Co S, et al. Health cobenefits and transportation-related reductions in greenhouse gas emissions in the San Francisco Bay area. Am J Public Health 2013;103:703-9.

10 Rojas-Rueda D, de Nazelle A, Andersen ZJ, et al. Health impacts of active transportation in Europe. PLoS One 2016;11:e0149990.

11 Rojas-Rueda D, de Nazelle A, Teixidó O, et al. Replacing car trips by increasing bike and public transport in the greater Barcelona metropolitan area: a health impact assessment study. Environ Int 2012;49:100-9.

12 Rojas-Rueda D, de Nazelle A, Teixidó O, et al. Health impact assessment of increasing public transport and cycling use in Barcelona: a morbidity and burden of disease approach. Prev Med 2013;57:573-9.

13 Woodcock J, Edwards P, Tonne C, et al. Public health benefits of strategies to reduce greenhouse-gas emissions: urban land transport. Lancet 2009;374:1930-43.

14 Woodcock J, Franco OH, Orsini N, et al. Non-vigorous physical activity and all-cause mortality: systematic review and meta-analysis of cohort studies. Int J Epidemiol 2011;40:121-38.

15 Woodcock J, Givoni M, Morgan AS. Health impact modelling of active travel visions for England and Wales using an integrated transport and health impact modelling tool (ITHIM). PLoS One 2013;8:e51462

16 Rojas-Rueda D, de Nazelle A, Tainio M, et al. The health risks and benefits of cycling in urban environments compared with car use: health impact assessment study. BMJ 2011;343:d4521.

17 Woodcock J, Tainio M, Cheshire J, et al. Health effects of the London bicycle sharing system: health impact modelling study. BMJ 2014;348:g425.

18 Strömgren M, Schantz P, Sommar JN, et al. Modeling commuter modal shift from car trips to cycling: Scenario construction and outcomes for Stockholm, Sweden. Journal of Transport Geography 2020;86:102740.

19 Stjernström O. The ASTRID data base and population geography (only in Swedish "Databasen ASTRID och befolkningsgeografi exemplen integration och barnfamiljernas geografi”). Geografiska Notiser 2011;69:79-86.

20 Schantz P, Wahlgren L, Eriksson JS, et al. Estimating durationdistance relations in cycle commuting in the general population. PLoS One 2018;13:e0207573.

21 Schantz P. Distance, duration, and velocity in cycle commuting: analyses of relations and determinants of velocity. Int $J$ Environ Res Public Health 2017;14:1166 doi:10.3390/ijerph14101166

22 Schantz P, Stigell E. A criterion method for measuring route distance in physically active commuting. Med Sci Sports Exerc 2009;41:472-8.

23 Schantz P, Wahlgren L, Eriksson JS, et al. Correction: Estimating duration-distance relations in cycle commuting in the general population. PLoS One 2019;14:e0218221.

24 Schantz P, Wahlgren L, Eriksson JS, et al. Correction: Correction: Estimating duration-distance relations in cycle commuting in the general population. PLoS One 2019;14:e0218866. 
25 Ainsworth BE, Haskell WL, Herrmann SD, et al. 2011 compendium of physical activities: a second update of codes and Met values. Med Sci Sports Exerc 2011;43:1575-81.

26 NBHW. The National board of Health and Welfare (Socialstyrelsen). Socialstyrelsen, SE-106 30 Stockholm, Sweden, 2013. Available: http://www.socialstyrelsen.se/statistics/statisticaldatabase/ causeofdeath [Accessed Jan 2017].

27 Rabl A, de Nazelle A. Benefits of shift from car to active transport. Transport Policy 2012;19:121-31.

28 Kelly P, Kahlmeier S, Götschi T, et al. Systematic review and metaanalysis of reduction in all-cause mortality from walking and cycling and shape of dose response relationship. Int J Behav Nutr Phys Act 2014;11:11.

29 Donaire-Gonzalez D, de Nazelle A, Cole-Hunter T, et al. The added benefit of bicycle commuting on the regular amount of physical activity performed. Am J Prev Med 2015;49:842-9.
30 Sahlqvist S, Goodman A, Cooper AR, et al. Change in active travel and changes in recreational and total physical activity in adults: longitudinal findings from the iConnect study. Int J Behav Nutr Phys Act 2013:10:28.

31 Mueller N, Rojas-Rueda D, Cole-Hunter T, et al. Health impact assessment of active transportation: a systematic review. Prev Med 2015;76:103-14.

32 Grabow ML, Spak SN, Holloway T, et al. Air quality and exerciserelated health benefits from reduced car travel in the midwestern United States. Environ Health Perspect 2012;120:68-76.

33 Götschi T, de Nazelle A, Brand C, et al. Towards a comprehensive conceptual framework of active travel behavior: a review and synthesis of published frameworks. Curr Environ Health Rep 2017;4:286-95.

34 Schantz P, Salier Eriksson J, Rosdahl H. Perspectives on exercise intensity, volume and energy expenditure in habitual cycle commuting. Front Sports Act Living 2020;2:65. 